\title{
Antonio Ramos Espejo y el primer cine de China
}

\author{
Juan Ignacio Toro Escudero
}

\section{Resumen}

El trabajo se centra en la participación fundamental de Antonio Ramos Espejo en varias etapas del nacimiento del cine chino, como responsable de muchas de las primeras películas realizadas en china, productor de algunas de las primeras películas realizadas en China por chinos, dueño de los primeros cines y lugares de proyección. También responsable de la distribución en el centro, este y sur del país durante las dos primeras décadas del siglo XX, y exhibidor de la gran mayoría de las primeras películas chinas. El autor destaca por otra parte la ausencia de estudios acerca de su vida y obra o la falta casi total de referencias con que cuenta quien decida dedicarse a ello, ya se hable de fuentes chinas o extranjeras; con la sugerencia finalmente por parte del autor del interés que tendría indagar acerca de las razones de que la práctica totalidad de los pioneros del cine en China viajaran con pasaportes de potencias de segunda categoría. En suma, por qué motivo tantos españoles protagonizan el amanecer del séptimo arte en China.

\section{Palabras clave}

Cine chino, distribución, exhibición, china, España, pionero español.

\section{Antonio Ramos Espejo and the first cinema in China}

\section{Abstract}

About of the fundamental participation of Antonio Ramos mirror at various stages of the birth of Chinese cinema, responsible for many of the first films made in china, producing some of the first films made in China by Chinese, the first business cinemas and projection. Also responsible for the distribution in the center, east and south of the country during the first two decades of the twentieth century, and merchandiser of most of the first Chinese films. The author also stresses the lack of studies about his life and work and the almost total lack of references available to decide to pursue it, and talk of Chinese or foreign sources; finally with the suggestion by the author of the interest that would inquire about the reasons that almost all of the pioneers of cinema in China with passports to travel second class powers. In short, for what reason so many Spaniards star in the dawn of the seventh art in China.

\section{Keywords}

Chinese cinema, distribution, exhibition, china, spain, spanish pioneer.

\section{http://dx.doi.org/10.5209/rev_CDMU.2013.v24.46366}

\section{INTRODUCCIÓN}

El próximo día 8 de septiembre se cumplirá el primer centenario de la inauguración del que sería durante décadas el principal cine de Shanghái y, por extensión, de toda China. El teatro vendría en Ilamarse Olympic, Cuadernos de Documentación Multimedia Vol. 24. 
seguramente por la proximidad de unos Juegos de Extremo Oriente, que se celebrarían un año después en la ciudad. Se ubicaba en Bubbling Well Road, importante arteria comercial que el Olympic contribuiría a situar como núcleo del entretenimiento en la capital del entretenimiento de Oriente, la Nueva York del Este -también llamada Londres del Este y París del Este en numerosas ocasiones-el auténtico centro cultural de China, la mítica Shanghái. El cine había sido diseñado por el arquitecto madrileño Abelardo Lafuente GarcíaRojo, recién llegado de una Manila estadounidense que hacía tiempo había dejado de ocultar su poco afán por favorecer la empresa española como en los viejos tiempos. De Manila también provendría el propietario del teatro, igualmente español, granadino en este caso: Antonio Ramos Espejo.

No serían los únicos emprendedores españoles en dejar Manila por la prometedora metrópolis china. Tampoco serían los únicos españoles relacionados con los albores del cine chino, pese a ser la española una colonia minúscula y no especialmente protegida. De igual manera, coincidirán también en el olvido casi absoluto que ha rodeado sus figuras, no obstante su importancia, hasta ya entrado el siglo XXI. Socios y amigos durante décadas, Ramos y Lafuente van ahora también de la mano en la reciente reivindicación de su notable implicación en el desarrollo de ese buque insignia de la modernidad que fue la Shanghái previa a la Segunda Guerra Mundial. Sin embargo por la trascendencia de su legado, por la amplitud, temporal y geográfica, de su empresa, por lo variado y completo de su labor, parece claro que entre los nombres de esa reducida pero activísima colonia española en Shanghái, hemos de destacar muy principalmente el de Antonio Ramos Espejo, quien entre los años 1903 y 1926 desarrolló la más destacada cadena de pantallas cinematográficas del país, dominó la distribución de películas desde Shanghái a Hong Kong, produjo algunos de los primeros documentales de China, fundó una de las primeras productoras de largometrajes de ficción de Shanghái y se consolidó como uno de los grandes empresarios del vodevil y las variedades en Asia Oriental. Acabada su etapa china, de vuelta a España en el otoño de 1927, todavía fundó el cine más moderno del país en su momento, el Rialto de la Gran Vía madrileña. Por si esto fuera poco, no hemos mencionado todavía la etapa por la que a día de hoy Ramos ha recibido mayor reconocimiento internacional, pese a lo incierto de estos acontecimientos y su magnitud y trascendencia discutibles, sus años en Manila, donde se le atribuye la realización de las primeras películas en la historia de Filipinas y las primeras proyecciones cinematográficas, en el Salón Leibman y Peritz. Realizaremos, pues, en este exiguo espacio, un somero acercamiento a la biografía y obra de Ramos Espejo, analizando ante todo su importancia como pionero principal del cine en China. 


\section{ALHAMA DE GRANADA Y FILIPINAS}

Antonio Ramos Espejo nació en Alhama de Granada el 3 de mayo de 1878, en el seno de una familia de posición acomodada que poco después cayó en desgracia económica, lo cual obligó a Antonio, segundo de siete hermanos, a alistarse voluntario en el primero de los batallones de cazadores que partirían a partir del verano de 1896 para Filipinas como respuesta a las revueltas independentistas que brotaban en el archipiélago.

Partió de Barcelona en el vapor Monserrat el 7 de septiembre de 1896, llegando a Manila el 6 de octubre tras casi un mes de viaje con escalas. Parece ser que en Manila fue destinado a oficinas, al ser uno de los pocos soldados que sabían leer y escribir. Este destino y su curiosidad por el nuevo invento francés del cinematógrafo, junto a su empeño en hacer fortuna, habrían posibilitado que, en agosto de 1897, fuera el responsable de las primeras proyecciones efectuadas en el archipiélago filipino con el aparato de los hermanos Lumiére. Meses antes, un cronofotógrafo proyectaba imágenes en el Salón Pertierra de Escolta ㅇ12.

Deocampo (2007: 45-47) señala que se atribuyen asimismo a Ramos los primeros registros realizados con la máquina Lumiére, que significarían las primeras películas del país, aunque él mismo duda de las fuentes, nada precisas y hoy ilocalizables.

En todo caso, parece cierto que Ramos se inició en el negocio cinematográfico en Manila y que, ante la falta de perspectivas de futuro con el dominio estadounidense, decidió partir para el continente, a la nueva tierra prometida para aventureros de todo jaez, la Shanghái de la Concesiones Internacionales.

\section{SHANGHÁI}

No sabemos en qué año llegó Ramos a Shanghái. En 1899 es de nuevo llamado a filas como miembro del Batallón Provisional de Cazadores de Bisayas y Mindanao con destino al sur del archipiélago, aunque es posible que no llegara a embarcar, pues sabemos que fue declarado desertor y luego indultado en 1913 (lo cual transforma asimismo la deserción en posible causa o aderezo para su mudanza a la ciudad abierta por excelencia, morada de refugiados de todo el orbe, en que se había convertido Shanghái). En 1903 lo encontramos en Shanghái ${ }^{1}$. Según Leyda (1972: 3), habria conocido en Shanghái a otro español, un tal Jialun Baike (en su transliteración en pinyin) que había intentado durante años prosperar en el negocio del cine sin demasiado éxito, de manera que acabaría regalando su equipo y películas al ambicioso Ramos. Ya hemos

\footnotetext{
${ }^{1}$ García Tapia (2009: 87), Shen (2005: 10). 
argüido en anteriores artículos sobre la auténtica identidad de este misterioso "Jialun", que Leyda quiere bautizar como "Galen Bocca", pese a lo muy aventurado de tal nombre para un español (y a que no exista registro alguno de nadie que pisara Shanghái con tal nombre), apostando por que se tratase de Bernard Goldenderg, socio de Ramos desde esa primera década del siglo hasta su trágica muerte, asesinado, en noviembre de 1922. Goldenberg, sefardita nacido en Singapur, nacionalizado español por las bondades que tal pasaporte tenía en Shanghái, al disfrutar sus poseedores de extraterritorialidad, es, como Ramos, unos de esos pioneros olvidados del cine chino, judío, como casi todos ellos, extranjero, como básicamente todos fueron, español, como Antonio Ramos, como Ramón Ramos, como Salomón Eskenazi, como los Cohen, como Matheo Beraha; y socio de Ramos Espejo, gerente de sus principales cines y de su empresa de producción, distribución y exhibición cinematográfica, la Ramos Amusement Company.

De acuerdo a Zhang (2010: 31) las primeras proyecciones de Ramos tuvieron lugar en la Tetería Tongan (同 安茶居) en la Calle Mayor (Damalu). Xue (2011: 140) sitúa esos comienzos en una pista de hielo, la primera de China, por cierto, en la calle Zhapu, previos a su paso por Damalu. Indiscutido es que a finales de año había alquilado una habitación en la popular tetería Qingliange (青莲阁) para la sola proyección de películas, lo que convertiría a ese salon en el primer espacio destinado exclusivamente de manera prolongada a la exhibición de cine abierto en China, principal motivo de reconocimiento de Ramos en la muy escasa literatura china dedicada a él.

El éxito de Qingliange habría posibilitado cinco años después la apertura en el popular barrio de Hongkew, con terreno más barato y mucha población, aunque de poco poder adquisitivo, del Hongkou Cinema, la otra hazaña oficial de Ramos hasta hace una década ${ }^{1}$, cuando aún se lo consideraba en círculos académicos como el primer teatro cinematográfico de China.

\footnotetext{
${ }^{1}$ En los últimos años han surgido varias voces que lo desacreditan como primer cine de China por la existencia de otros teatros en Pekín y Tianjin, pero siguen apareciendo publicaciones que inciden en este título de pionero para el Hongkou Cinema, cual acredita también el hito instalado en su ubicación ("Being the first cinema in modern China, originally named Hongkew Film and Drama Garden, the cinema was built in 1908 and formally opened to the public with the show of a Western film, The Nestle of Dragon on Dec. $22^{\text {nd }}, 1908 . "$ ), entre las calles Zhapu y Haining, levantado por la ciudad de Shanghái. Por nuestra parte, hemos demostrado que hubo un cine anterior, el Colón, perteneciente también a Ramos, que muy probablemente fuera el primero de China.
} 
Sin embargo, no hemos podido encontrar notas de tal inauguración en la prensa del momento, ya sea china, rusa, francesa o inglesa. Se debe esto a que Antonio Ramos ya tenía año y medio antes un cine en el mismo número de la misma calle donde se supone que se inauguró el Hongkou en diciembre de 1908: el Colon Cinematograph.

El Colon es un muy firme candidato al honor de figurar como primer cine del país, pero este descubrimiento, al igual que tal reconocimiento, como decimos uno de los pilares de la reducida presencia de Ramos en los tratados de historia del cine chinos, no pasa de ser anecdótico en la carrera del granadino en Shanghái y otras ciudades de China y Oriente, es más.

El Colon fue únicamente el primero de una cadena de teatros que Ramos conformaría en años sucesivos, no solamente en Shanghái, sino también en otros puertos abiertos del país. En 1909 abriría el primer teatro moderno con estándares internacionales de China, el Victoria Theatre (維多利亞, Weiduoliya), en el no 24 de Haining Rd. North; en 1914 llegaría el Olympic (夏令配克, Xialingpeike), el más lujoso de su tiempo en China y cine de referencia en Shanghái durante décadas, ya sea con este nombre, como Embassy, como Roxy o como teatro nuclear de la propaganda japonesa durante la ocupación de la ciudad en los años 30 - 40, en el 127 de Bubbling Well Road (Jian'ansi Road, 静安寺路). Poco después, en 1917, fundaría el National (Wanguo, 萬國 o 万国, en East Xihuade Rd., hoy Dong Chang Zhi Lu, 367). Ese mismo año, Ramos inauguró el cine Carter (Kade, 卡德, en Carter Road, hoy cruce de las calles Xinzha y Shimener). Finalmente, abrió en 1921 el Empire (恩派亚, Enpaiya) en Xiafei -Joffre- Avenue. En 1922, con el asesinato de su amigo, padrino de boda y socio en el negocio cinematográfico desde sus inicios, Bernardo Goldenberg, español sefardita, como se dijo, Ramos adquirió su China Theatre, 中國, inaugurado por Goldenberg en $1920^{1}$ en la actual Wuzhou Lu 150. Incluimos a continuación un mapa que detalla la ubicación de los cines propiedad de Ramos.

\footnotetext{
${ }^{1}$ Vid. Wang, Runyong (1994), "Shanghai Yingyuan Bianqian Lu," ("History of the changes in Shanghai's film theatres"), p. 85, citado en Zhang (2009: 45).
} 


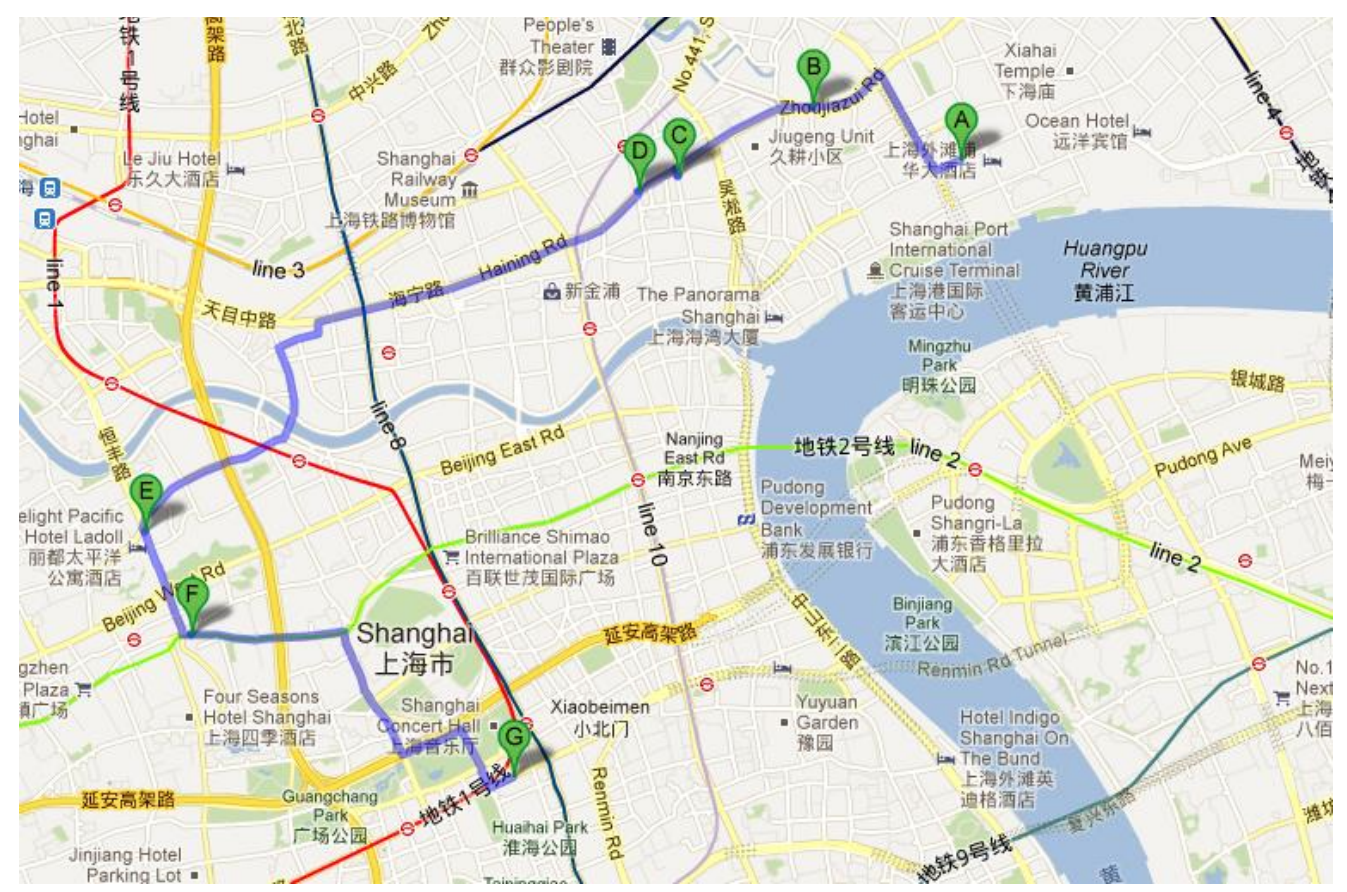

A. National, B. China, C. Colón Cinematograph y Hongkew, D. Victoria, E. Carter, F. Olympic, G. Empire.

Como se puede observar, desde muy pronto buscó Ramos la diversificación de su público situando sus pantallas en diferentes zonas de la ciudad, a las que indefectiblemente llegaba el tranvía, teniendo siempre en cuenta su público potencial y su segregación por clases, gustos y nivel adquisitivo. De esta manera, y dado que controlaba a través de su Ramos Amusement Company así mismo la distribución de películas en la ciudad, estableció una cadena con cines de estreno, de segunda y tercera ronda, aprovechando de esta manera en sus propios teatros la vida de la película (que se desgastaba sesion a sesion) al máximo, y haciéndola llegar a toda la audiencia posible, incluida la población china, muy mayoritaria en la ciudad y no obstante olvidada por los demás exhibidores hasta los años 20. A continuación, arrendaba la película en teatros chinos de aun menor categoría o la distribuía por provincias.

\section{OTRAS PROVINCIAS CHINAS}

En la capital de la China central, Hankow, con solo dos cines hasta los años 20, tenía Ramos también el Palace, como figura en el logo de su empresa, la Ramos Amusement Co., que en 1926 incluía los ocho cines mencionados. El Palace era administrado por E. Hermida, español y muy probablemente agustino recoleto, y, aunque ignoramos la fecha de su inauguración, podemos afirmar que en 1925 estaba ya en funcionamiento. 
No fueron estos, sin embargo, los únicos cines de Ramos, suficientes para que la historiografía china le haya concedido el título de "Rey del Cine Chino" sin conocimiento de sus empresas previas en el sur del país. En efecto, la primera década del siglo XX vio nacer la Ramos \& Ramos, primera empresa de que se tiene constancia constituida por Antonio Ramos y el valenciano Ramón Ramos. La Ramos \& Ramos, también conocida como "Ramos Brothers" en la prensa de la época es a un tiempo una agencia de contratación de talentos para el vodevil y los espectáculos de variedades tan extendidos en esa época, con oficinas en Sidney, Manila, Tianjin, Pekín, Shanghái y Hong Kong, y una empresa de distribución cinematográfica, propietaria de varios cines en Macao, Hong Kong y Shanghái y responsable, por ejemplo, de la llegada de las primeras películas españolas a China de que tenemos constancia. La prensa australiana y estadounidense del momento la hace la única empresa fiable de Asia junto a la de Hertzberg, otro de los pioneros olvidados del cine chino.

Ramos y Ramos contaron cuanto menos con tres cines en Hong Kong, el primero realmente digno de ese nombre con parámetros modernos de calidad y comodidad incluido, y al menos dos en Macao hasta bien entrada la década de los años 10. Desaparece entonces la figura de Ramón Ramos, de igual apellido pero ninguna relación consanguínea con Antonio, aunque se fundirán ambas, la de Antonio y la de Ramón, en el imaginario tenebroso de la prensa estadounidense cuando, recién comenzada la década de los 20, emprenda una campaña de acoso y derribo de su empresa china dentro del avance americano por la conquista del mundo a través del cine que irrumpe sin trabas tras la Gran Guerra. La campaña concluirá con el cruento asesinato del español Bernardo Goldenberg en el cine Victoria, el asentamiento de las principales majors americanas en Shanghái y el inicio del fin para el emporio de Ramos Espejo.

Todavía efectuaría un intento de supervivencia con su entrada en la producción cinematográfica en $1923^{1}$, sección de su empresa que dirigía precisamente su socio Goldenberg, con relativo éxito, pero solo la crisis financiera demoraría su retorno a España hasta 1927. La salida de Ramos del país, que supuso el alquiler de sus pantallas a la emergente Mingxing, significó una gran ayuda para la naciente industria nativa, que heredó así una empresa estructurada, diversificada, con intereses en produción (contaba con su propio estudio

${ }^{1}$ Con la realización de un largometraje dramático y varios cortometrajes cómicos. A este respecto, hay que señalar que desde un inicio realiza Ramos, normalmente a través de su socio Amerigo Lauro, cineasta y empresario cinematográfico italiano, pequeñas piezas documentales o noticiosas con actualidades de la ciudad y el país que exhibe en sus cines como inicio de sesión. Incluso llevaban estas películas el nombre de su cine de cabecera en aquellos inicios, el Victoria, y se exportaban cuando menos a Hong Kong. 
acristalado al modo parisino), distribución y exhibición. La Mingxing se erigió de esta forma como faro de la industria china y Ramos regresó a su país con un capital muy importante, dispuesto a nuevas inversiones en los campos que lo hicieron millonario: el cine y el Mercado inmobiliario.

En Madrid, levantó el cine Rialto en la Avenida de Eduardo Dato, edificio culminado por varias plantas de viviendas que vendió o alquiló, a excepción de una, en la que residiría hasta su muerte en 1944. Antes, volvería en 1931 a Shanghái a finiquitar sus negocios y propiedades en China. Uno de sus cines, el primero, el Hongkew, quedaría en manos españolas. Salomón Eskenazi y Matheo Beraha, ambos sefarditas nacionalizados españoles, se encargarían del viejo teatro de Ramos. Beraha también abriría otros dos cines, en 1930 y 1933, a través de la empresa Cineco, en la que eran accionistas también la Española Linda Cohen o Ladzlo Hudec, el famoso arquitecto.

\section{CONCLUSIONES}

Conocida la participación fundamental de Antonio Ramos Espejo en varias etapas del nacimiento del cine chino (responsible de muchas de las primeras películas realizadas en china, productor de algunas de las primeras películas realizadas en China por chinos, dueño de los primeros cines y lugares de proyección, responsible de la distribución en el centro, este y sur del país durante las dos primeras décadas del siglo XX, exhibidor de la gran mayoría de las primeras películas chinas, etc.) cabría preguntarse los motivos de la ausencia de estudios acerca de su vida y obra o la falta casi total de referencias con que cuenta quien decida dedicarse a ello, ya se hable de fuentes chinas o extranjeras.

También sería de interés indagar acerca de las razones de que la práctica totalidad de los pioneros del cine en China portaran pasaportes de potencias de segunda categoría, solo adyacentes a los países verdaderamente dominadores del mercado cinematográfico, que eran también los dominadores del planeta. En concreto, ¿̇por qué tantos españoles protagonizando el amanecer del séptimo arte en China?

Las razones para lo primero son esencialmente politicas. China relegó cualquier producción cultural previa a su gloriosa revolución comunista al olvido más absoluto. La gran obra recopilatoria de toda la Historia del Cine Chino, Zhongguo dianying fazhan shi (Historia del desarrollo del cine chino), escrito por Jihua Cheng, Shaobai Li y Zuwen Xing y publicado por primera vez en Pekín en 1963, incluía toda reflexion desde un punto de vista socialista, y reparaba únicamente en los aspectos marxista-maoístas de su cine, rechazando por defecto las eras "feudales" o "contrarrevolucionarias". La exaltación nacionalista que vive desde entonces el país hizo el resto. Los inicios del cine chino son extranjeros necesariamente, como lo era el propio cinema, y la academia china continua bajo un control politico solamente relajado en las últimas décadas. 
De igual manera, el que no fueran anglosajones los protagonistas de este albor de la cinematografía en China ha frenado el interés por su análisis y estudio, por la oposición que constituye a la creciente reformulación de la Historia en términos de total centralidad del mundo anglosajón, y por la abundancia de fuentes en chino, francés, español y otras lenguas no accesibles por lo general para el académico dominante.

En cuanto a la segunda de las cuestiones, ¿por qué dos españoles, un italiano, un portugués de origen ruso y un ucraniano fueron los pioneros del cine en China, autores de prácticamente todos sus hitos y avances durante sus primeras dos décadas? ¿Por qué tres de ellos eran judíos? La respuesta la da la cuna de este cine chino: la Shanghái, refugio de aventureros, hogar de exiliados, amparo de prófugos. El cine en sus inicios, especialmente en China, era destino para aventureros, gentes deseosas de jugar con el riesgo y adaptables a los envites de la modernidad. No era en absoluto un negocio seguro y pocos previeron siquiera de lejos sus posibilidades. Shanghái era una ciudad gobernada por ingleses, estadounidenses y franceses, donde el resto de nacionalidades sobrevivía generalmente agrupándose en guetos culturales al dominio de las potencias regentes. El español, el italiano, el ucraniano errante, el judío rechazado, aprovecharon su oportunidad, encontrada en bolas de cristal muy opaco y convenientemente arrebatada cuando el horizonte aparecía despejado de toda duda, dorado y sostenido por agresivas políticas comerciales desde Washington. Para entonces, tanto Ramos como Brodsky, como Hertzberg estaban ya de retirada y habían acumulado lo suficiente para soñar con nuevas empresas vitales. Otros, Goldenberg, quedaron por el camino.

\section{BIBLIOGRAFÍA Y REFERENCIAS}

BARNOUW, Erik (1993) Documentary: A History of the Non-Fiction Film. Oxford University Press: Nueva York, EEUU.

CHEN, Wenping \& Jifu CAI (2007) 上海电影一百年序，上海文化出版社. Shanghai Dianying 100 Nian Xu. Shanghai Wenhua Chubanshe. Shanghai: China.

CHENG, Jihua (Ed.) (1963) 中國電影發展史, 中国电影出版社, Zhongguo diangyin fazhan shi, Zhongguo dianying chubanshe. Beijing: China.

CURRY, Ramona (2011) “Benjamin Brodsky (1877-1960): The Trans-Pacific American Film Entrepreneur -Part One, Making A Trip Thru China" Journal of American-East Asian Relations 18, pp. 58-94, California, EEUU.

DEOCAMPO, Nick (2007) Cine. Spanish Influences on Early Cinema in the Philippines, Anvil Publishing Inc., Manila, Filipinas.

GARCÍA-TAPIA BELLO, José Luis (Septiembre de 2009) “Presencia (y ausencia) española en China hasta 1973”, Boletín Económico de ICE no 2972. Información comercial española, pp. 71-93. En línea) Recuperado el 25 de julio de 2014 de 
http://www.revistasice.com/cachepdf/BICE 2972 71-94 F86DF1F66C513F6FF5D2B57947F61931.pdf

HUANG, Xuelei (July 2009) Commercializing Ideologies. Intellectuals and Cultural Production at the Mingxing (Star) Motion Picture Company 1922 - 1938, PhD Dissertation in "Chinese Studies" in Heidelberg University (Germany). En línea) Recuperado el 25 de julio de 2014 de:

http://archiv.ub.uni-heidelberg.de/volltextserver/frontdoor.php?source opus=10406

LEYDA, Jay (1972) An Account of Films and the Film Audience in China, MIT Press, Cambridge, MA, USA

LI, Shaobai (2003) 影视榷略-一电影历史及理论续集, 文化艺术出版社, 北京振兴华印刷厂印刷. Beijing: China.

LU, Tiemin (1999) 旧上海影业大王雷玛斯的发家史，世纪. Beijing: China.

MCKERNAN, Luke (1996) "Antonio Ramos", in BUSCOMBE, Edward (Ed.) Who's Who of Victorian Cinema: A Worldwide Survey, British Film Institute. En línea, recuperado el 24 de Julio de 2014 en: http://www.victorian-cinema.net/ramos.htm

MIN, Jie (1998) 近代中国社会文化变迁录, Jindai Zhongguo shehui wenhua bianqian lu, Hangzhou: Zhejiang renmin chubanshe. China.

SHEN, Yun (沈云) (2005) Actividades Comerciales en la Época de Nacimiento del Cine, 1896-1922) Zhao, Shi (Ed.), Editorial de Cine Chino. 电影萌芽期的商业活动 (1896-1922), 中国电影出版 Dianying mengyaqi de shangye huodong, Zhong Guo Dianying Chubanshe

SUYUAN, Li \& Hu JUBIN (1997) Chinese Silent Film History. Editado por Rui Wang y Tabethe Miller. China Film Press: Beijing. China.

TORO ESCUDERO, Juan Ignacio (June 2011) “Antonio Ramos Espejo y la comunidad española del Shanghái de inicios del siglo XX", Serie de Conferencias Precursores: uniendo las orillas de un mismo continente, Instituto Cervantes de Pekín, Beijing: China.

TORO ESCUDERO, Juan Ignacio (2012) La participación española en los inicios del cine chino en Shanghái (1896-1937): Antonio Ramos Espejo (1878-1944). Final MA Dissertation. Master of Arts in Spanish Cinema Studies. Rey Juan Carlos University. Madrid: Spain.

XUE, Feng (2011) “雷玛斯与上海电影产业之创立” (“Leimasi yu shanghai dianying chan ye zhi chuang li”,) 电影艺术，pp.140-145. Beijing: China.

ZHANG, Qian (2009) From Hollywood to Shanghai: American Silent Films in China, Tesis doctoral aprobada en la Universidad de Pittsburgh, tutorizada por Ronald J. Zboray. Pittsburg, Pennsylvania, EE.UU.

ZHANG, Xinmin (2010) “电影与近代上海市民娱乐”,"Film and Entertainment in nowadays Shanghai” en Joint Seminars from Shanghai Normal University and University of Osaka, December $6^{\text {th }}, 2009$, University of Osaka. pp. 22-35. 